\title{
“Can Disability Be Positive?" Reflecting on Children's Rights and Disability through Shaking the Movers: A Youth-led, Consultative, Collaborative, Participatory Model
}

\author{
Daniella Bendo \\ Doctoral Candidate, Law and Legal Studies \\ Carleton University, Ottawa, Ontario, daniellabendo@cmail.carleton.ca
}

\begin{abstract}
This article takes a reflective approach from the perspective of the National Coordinator of a youth-led consultative and collaborative model known as Shaking the Movers, developed by the Landon Pearson Resource Centre for the Study of Childhood and Children's Rights at Carleton University in Ottawa, Ontario.i Through the use of autoethnography, it reflects on the model that was used to run a workshop that focused on children's rights and disability to explore the guiding question: "can disability be positive?” It reveals how the event unfolded, key messages from working with children and youth with disabilities, how the model worked or instances when it did not, and key components that are helpful for others who may be interested in organizing a youth-led consultative and collaborative workshop with young people with disabilities.

Ultimately, the paper explores the concepts of marginality and relationality and the ways these notions highlight how adult-centric views creep into the best-laid efforts of adults who are aware of the strength of youth-led workshops.
\end{abstract}

Keywords: disability, children's rights, participation, children, youth 


\section{Introduction}

Can disability be positive? This provocative question framed a two-day youth-led workshop known as Shaking the Movers (STM) that centered on children's rights and disability, which was held at Carleton University in Ottawa, Ontario on October 13-14, 2018. The workshop was hosted by Dr. Virginia Caputo (Carleton), co-investigator on a Social Sciences and Humanities Research Council of Canada Partnership grant for the Inclusive Early Childhood Service System Project (IECSS) led by Project Director Dr. Kathryn Underwood (Ryerson University).ii The participants at the IECSS/STM workshop comprise the youth advisory council for the IECSS nation-wide research project focusing on disability and early childhood. The guiding question was initially proposed by an adult steering committee in an attempt to explore and unpack the stigma surrounding disability, based on the researchers encounters within different communities. In order to directly explore these encounters, the researchers decided to use this question as a guiding framework for the workshop.

Collectively, as the youth facilitators reflected on the guiding provocative question, "can disability be positive?" their stories and perspectives highlighted how the concepts of marginality and relationality work to penetrate their everyday lives as well as the lives of those around them. In the context of this paper, I concur with Sue (2010), who refers to marginality as the unequal treatment of marginalized social groups, particularly individuals with disabilities, which often leads to unequal social justice, opportunities, and status. Such circumstances serve to socially devalue certain groups, exclude them, and confine them to the margins of society - culturally, socially, and politically. While recognizing that marginality itself is a relation (Goodley, 2012), I refer to the term relationality as the connection or relation between people and objects. In this case, I focus on the connection between experiences of marginality and how relationality works to both enhance or detract from marginal experiences. For instance, I witnessed how youth reconceptualized the concept of marginality and what margins mean in different contexts. They highlighted how focusing on relationality moves the view away from the focus on individuals in order to take a broader view of their lives. Together, marginality and relationality worked to disrupt adult-centric views about young people and disability. The workshop demonstrated that marginality ultimately shapes their relational experiences of the world, which, in turn, shapes environments, interactions, and relationships for us all as researchers and professionals working with young people. 
The following article makes use of autoethnography, which is an approach that describes and explores personal and cultural experiences (Ellis, 2004; Ellis \& Bochner, 2000; Wall, 2008), using a self-reflective lens from the perspective of the National STM Coordinator working with children and youth with disabilities. Through the use of narrative writing, a method that has been used within autoethnography to narrate personal experiences (Clandinin \& Connelly, 2000), I highlight how the event unfolded, what I learned from working with children and youth with disabilities, what surprised me, how the model worked, instances when it did not, and key takeaway messages that I believe are important for others who intend to organize a youth-led consultative and collaborative workshop with young people with disabilities. The use of autoethnography was important in understanding my personal experiences working with young people with disabilities in order to understand political and cultural experiences more broadly (Ellis \& Bochner, 2000). Ultimately, the paper explores how the concepts of marginality and relationality work to highlight how adult-centric views creep into the best-laid efforts of adults who are aware of the strength of youth-led workshops.

\section{Shaking the Movers}

Over the past three years, I have worked for the Landon Pearson Resource Centre for the Study of Childhood and Children's Rights (LPC) as the National Coordinator for a youth-led consultative and collaborative model known as STM. Housed in Carleton University, the LPC facilitates dialogue, initiatives, and projects dedicated to the advancement and betterment of the lives of children and young people. One initiative emerging out of the centre is known as STM. STM is a youth-led, youth-driven consultative and collaborative child and youth participation model. The model adopts a rights-based approach to provide children and young people with a unique opportunity to exercise their right to engage in important civil and political processes. Framed by the United Nations Convention on the Rights of the Child (UNCRC) Guiding Principles and Provision Articles, STM's design fosters children's participation and cautiously transfers power to children who are central to the model's design (Caputo, 2018). The model recognizes children's rights as relational and adopts a complementary approach to children's rights to foster an interactive and collaborative approach between children and adults. Adopting a rights-based and participatory approach, the model complies with children's rights scholar and advocate Gerison Lansdown's nine essential components of quality participation; she states that quality participation should be: transparent and informative, relevant to children's rights, 
voluntary, respectful, child friendly, inclusive, supported by trained adults, safe and sensitive to risk, and accountable to children (Caputo, 2018). The model can be adapted in contexts that aim to establish collaborative consultation with young people (Pearson \& Collins, 2011).

Since 2007, the LPC has been hosting annual nation-wide STM workshops to gain young people's perspectives on rights-based themes stemming from the UNCRC. Workshops are held in British Columbia, Ontario (including Toronto and Ottawa), New Brunswick, and Québec. In the fall of 2019, there will be workshops held in Alberta and Nunavut with young children aged four to six. The workshops are structured over two days of interactive encounters with children and youth up to the age of 18 . Youth facilitators meet prior to the workshop to design the rightsbased activities and discussions and then implement and guide the workshop of up to 30 interested participants. During the first day of the workshop, the youth facilitators and participants gather during the evening for introductions, while the remainder of the workshop is spent in intensive discussion (Pearson \& Collins, 2011). Based on the workshop theme, the discussions are broken down into sub-themes where youth can focus in depth on their particular interests.

The "Can Disability be Positive?" workshop was organized into three main themes based on the participants' and facilitators' interests: (1) Advocacy and Identity, (2) Education and Participation, and (3) Involvement in Communities. One rights-based activity that was carried out in the Advocacy and Identity group included the use of information sheets that a student developed (see Appendix 1, Benincasa, St. Dennis, \& Caputo, 2018) on the UNCRC and the United Nations Convention on the Rights of Persons with Disabilities (UNCRPD). The facilitators used the information sheets with the participants and designed a beach ball game to foster discussion on rights and lived experiences. The beach ball had different articles of the Conventions drawn onto it and was then tossed around in the group. Participants shared challenges they faced regarding some of these rights and moments when adults would make decisions about their lives based on generalized understandings of their disabilities (McGuire, 2016; Oliver, 1990). They also reflected individually and collectively in the group about the constant challenges they faced accessing services (Benincasa, St. Dennis, \& Caputo, 2018). The facilitators used their feedback to discuss ways to change the social perception of disabilities. While the smaller groups engaged in separate discussions based on the selected theme for certain parts of the day, the entire larger group also came together at different points to share their 
discussions collectively. One activity carried out with the larger group was a discussion that asked participants to reflect on the following questions: "If you could have a superpower, what superpower would it be? How would you use it to help youth with disabilities?" The youth participants offered creative responses that demonstrated their remarkable compassion for the participants at the workshop. For example, youth provided the following perspectivesiii:

"I would have one hundred hands so that I could do more research about disability."

"I would have the power to secretly change people's attitudes towards disability."

"I would create an alternative reality where difference is accepted."

"I would have the power to know every language including American Sign Language."

"I would teleport and help everyone avoid inaccessible transportation systems."

"I would have the power to make drawings come to life so that I could just draw an accessibility device when someone needed one."

"I would be extremely wealthy so that I could buy everyone the devices they need."

The key messages from STM workshops are captured in reports that are distributed widely to child rights academics, educators, activists, advocates, policy makers, legislators, and parliamentarians to 'Shake the Movers' (Pearson \& Collins, 2011). The Child Rights Academic Network), which is comprised of over 65 child rights academics from across Canada and the UK, gathers annually to listen to what young people have to say and respond to their recommendations and insights. For this workshop on children's rights and disability, an additional 'Movers' event was held that invited over 50 adults who make decisions on behalf of young people with disabilities or who are deaf, to listen to a special presentation by youth participants at the end of Day One of the workshop. To prepare for the Movers forum, youth participants rejoined their small groups to begin planning their short presentations. Facilitators introduced different formats they might use, including spoken word, music, role-playing, and skits, to communicate what they had to say about the issues. Each of the three groups decided to write a skit to illustrate their perspectives on the themes. The youth participants addressed each of the three themes discussed during the day. Once the presentations were over, participants and facilitators joined different tables to have discussions with the Movers about their presentations. At the end of the event, Movers were asked to note on a card one thing that they had learned from the youth participants at the STM event and one way in which they would try to incorporate 
what they had learned in the work they do. These cards were collected and they became the basis for the conversations and discussions during Day Two of the workshop.

Since 2007, in addition to the theme of children's rights and disability, some of the other rights-based workshops have focused on the themes of children's rights and civil and political rights, identity and belonging, education, media, youth justice, mental health, play and artistic expression, exploitation, climate change, children on the move, and discrimination.

As the National STM Coordinator, my role has entailed designing and administering rights-based training for youth facilitators, supporting youth facilitators, networking with provincial STM organizers, attending nation-wide STM workshops to engage with youth facilitators and participants, organizing logistics of the workshops, and simply listening attentively to what children and youth would like Movers to know about their lived experiences that pertain to rights-based topics. Since my time in this role, the workshops have focused on the themes of children's rights and climate change, the rights of children on the move, and children's rights and discrimination. As well as co-ordinating the LPC's regular annual workshop series, I was invited to assist with a special project for a research team based at Ryerson University, the Inclusive Early Childhood Service System project (IECSS). The IECSS wanted to adopt the STM model to facilitate a workshop that focused on children's rights and disability. Given my previous background working as a youth inclusion specialist and my interests in children's rights and disability, I was hired as a research coordinator to help organize the event.

On October 13-14, 2018, the IECSS, in partnership with the LPC, hosted a two-day youth STM workshop on children's rights and disability. The goal of the IECSS is to examine how early childhood institutions are understood from the standpoint of families and children when they have a disability, and to re-consider what it means to have healthy institutions that are informed by the standpoint of those who may be most harmed by those institutions. In partnering with IECSS, the workshop adopted STM to offer an inclusive and accountable method for working with children and young people in planning and designing research on children's experiences of disability and early childhood institutions. The event took place at Carleton University with the objective of hearing from young people about their ideas and perspectives on their lived experiences of disability, using a rights-based approach. Youth facilitators were recruited from across the country to lead in the design and facilitation of the workshop, which hosted 30 children aged 10-18. Participants were also recruited from across Canada. All of the 
facilitators and participants identified as having a disability or disability experience, as deaf, or as having gifts (consistent with the Indigenous worldview).

\section{"Can Disability be Positive?"}

In Reclaiming Disability: Knowledge and Identity, Simi Linton (1998) reveals how academic literature up until the mid to late 19th century focused on limited and negative perceptions of disability. Her work served to re-conceptualize and develop the field of disability studies with a view to understanding positive aspects of disability and its relation to a range of different fields of study, not just applied or medicalized fields. In advocating to incorporate and explore the perspectives and viewpoints of people with disabilities into research and the field more broadly, Linton (1998) pointed to the potential of disability studies to enrich the understandings of human experience by learning from individuals with lived experiences. Other scholars have also critiqued dominant discourses on disability that provide negative and narrow conceptions; they have pointed to the cultural locations of disability, which have generated understandings of experiences on behalf of people with disabilities, without considering their own perspectives (Snyder \& Mitchell, 2005). Certain locations of disability include research, media, systems, institutions, and policies (Snyder \& Mitchell, 2005). While acknowledging that an abundance of disability studies literature has focused on exploring and deconstructing how disability can be positive (Linton 1998; Snyder \& Mitchell, 2005), this article is unique in that it reflects on young people's perspectives of their lived experiences with disabilities. I start by reflecting on what young people at STM taught me and how they challenged me to think and rethink about the guiding question "can disability be positive?" in questioning power relations between children and adults; specifically, in relation to the concept of child and youth participation.

One of the main tensions I observed during the workshop was the difficulty in transferring power from adults to the child and youth participants, despite the unique key objective of the STM model being to transfer power from adults to children (Caputo, 2018; Pearson \& Collins, 2012). One of the key components of STM is that adults are to relinquish control of the workshop so that the youth facilitators have a space to lead and collaboratively engage in discussions and activities with the participants (Caputo, 2018). I did not worry or deliberate about the potential barriers to achieving this objective, as we had achieved this power transfer many times in the past with the original STM workshop series. This time, however, our 
attempt to transfer power from adults to children with disabilities proved to be challenging because many of the adults who were spokespersons, chaperones, or primary caregivers for the children had a difficult time relinquishing power, for many different reasons.

For example, when we requested that the adults drop off their children in the morning on the first day of the workshop, many of them decided to stay on site for the full workshop. None of the parents actually participated in the workshop, given that the objective of the event is strictly for adults to listen to young people's perspectives, but once they arrived, a lot of the parents hesitated to leave the site. Compared to other workshops in the series, this was not a typical response from caregivers and went against one of the model's central aims, to transfer control from adults to children. For caregivers of deaf children, the adults were concerned about FM receivers functioning properly so their children could hear. For deaf children, who often interact with interpreters to communicate, it was not possible for adults to surrender their role or presence as individuals who acted as key facilitators of communication throughout the workshop. For children who were required to take complex medications and who relied on the adults to administer their medication, the parents were being cautious because they wanted to ensure their child took their medications at the correct time and in the appropriate manner. For some children who had complex allergies, the adults wanted to ensure they could ask questions of the catering staff, to ensure the food was safe for their children. Some children who were used to having the adults around for support wanted them to stay so that they could feel comforted. Of course, such situations occur regularly for many children and youth, but in this instance what was distinct for these children was how it raised the question of access intimacy (Mingus, 2011) and relationality with adults. In relation to the concept of interdependency, disability justice writer and educator Mia Mingus refers to the concept of access intimacy, which she describes in her 2011 essay:

Access intimacy is that elusive, hard to describe feeling when someone else "gets" your access needs. The kind of eerie comfort that your disabled self feels with someone on a purely access level. Sometimes it can happen with complete strangers, disabled or not, or sometimes it can be built over years. It could also be the way your body relaxes and opens up with someone when all your access needs are being met. It is not dependent on someone having a political understanding of disability, ableism or access. (para 4, p. ?) 
The concept of access intimacy is important to understanding interdependency and how it worked (or did not) in unique ways throughout the workshop. I recognized that adopting the STM model to step outside of interdependency was difficult for the children and for the adults on whom they relied so heavily. This prompted me to think about the model's objective to achieve child participation and refigure adult-child power relations, which posed the following questions for further reflection: how does access intimacy work when there is an adult/child power imbalance, and how do children negotiate independence while relying on others to meet their access needs? Although the STM approach has worked well with other groups of children and youth, attempting to implement it with children with disabilities proved to be challenging because the model did not recognize their interdependency as well as the power imbalances that exist between children and adults. Despite the challenges, both the youth facilitators and the participants found ways to gain control and power in the workshop in a way that enabled them to share their perspectives on the difficulties they face. The children and youth provided reflections on the importance of their participation and shared their lived experiences to highlight how they often feel silenced as individuals. Consider the following quotesiv:

"The thing that is the most frustrating is being left out of the conversation. I am right there and everyone is fighting about accommodations and no one bothers to ask me. Even when I speak up, they don't seem to want to listen."

"Decisions about our lives are being made based on generalized understandings of disability."

"They always make decisions on my behalf and I don't always understand what they want me to agree to."

"People should talk to youth themselves rather than just talk to their parents." "Bring young people with disabilities into discussions more often. Right now, youth sometimes have a hard time finding a voice because adults have a thumb on this."

The excerpts reveal that children and youth with disabilities often feel frustrated with the lack of power, agency, voice, and participation that they have in decisions that affect their lives. What came from my observations was the realization that, as researchers, practitioners, and professionals working with children and youth with disabilities, it is important to critically reflect on the ways that we sometimes assume what children with disabilities want or need. Indeed, 
these ideas may sometimes be accompanied by what may seem like good intentions to help support children with disabilities, as evidenced by helpers' desire to speak on behalf of children, make decisions based on what they believe is in their best interests, or engage in protective practices to ensure safety. However, as McGuire (2016) reveals, these practices can sometimes serve to govern and control children and youth with disabilities, which ultimately silences their viewpoints and perspectives. McGuire (2016) points to how mothers' desire to act as 'good' caregivers, who have the skills, qualifications, dedication, and time to ensure 'proper' child development, can often lead to extremely controlling behaviour. In listening to children and youth at the workshop reflect on the ways they often felt silenced by the very individuals who were supposed to be helping them, I felt challenged to reconsider the helpful/harmful relationship between children with disabilities and their caregivers, as well as the enabled/disabled dichotomy. These observations are in line with Oliver (1990), who suggests that the way disability is conceptualized has a direct link with how individuals with disabilities are treated:

As far as disability is concerned, if it is seen as a tragedy, then disabled people will be treated as if they are the victims of some tragic happening or circumstance. This treatment will occur not just in everyday interactions but will also be translated into social policies which will attempt to compensate these victims for the tragedies that have befallen them. (p. 2)

Young people at the workshop expressed how they felt excluded or silenced not only by helpers but also by policies that often operate as sites of power to exclude or govern their actions, based on limited understandings of disability. By reflecting on the guiding question "can disability be positive?" the children and youth highlighted that the ways in which disability is defined and understood have direct implications for the ways they are treated. In thinking critically about how to work with children with disabilities in meaningful ways, my observations and experiences with the STM workshop prompted me to think about the following questions: If the model asks adults to relinquish their power and control with children and youth, what happens to those who require assistance from adults? How can we ensure that children with disabilities are able to participate or want to participate in ways that we as researchers consider meaningful? What is meaningful participation and how can it be fostered for children and youth with disabilities? The workshop demonstrated that when adults relinquish power and control to 
children and youth, whether young people require assistance from adults or not, young people often exercise agency that leads to insightful and unique recommendations and perspectives, which are often silenced when this transfer of power does not occur.

Despite the challenges, I also observed how the interdependent relationships between these children and their interpreters, chaperones, and caregivers could also be positive. For instance, not only did the deaf children rely on their interpreters, but their interpreters also relied on the children, in unique ways. As one example, the children indicated when they had something to say and the interpreters followed their lead and generated conversations that the children controlled and led. Throughout the workshop, I watched how these children and youth challenged adult-centric views and created their own unique pathways of participation. One child resisted participating in some of the organized workshop activities. She asked facilitators to: "Just let me play, because sometimes when children play, they are telling you what they think."

Many of the children and youth said that they often felt enabled, as opposed to disabled, because they could do things that people without a disability could not. For instance, one participant spoke about her ability to turn her hearing aids off in order to tune out the world. Other participants talked about their ability to read with their hands in ways that others might not be able to. They spoke about their ability to speak a different language (American Sign Language), which made them feel empowered because others might not be able to engage in the same way. The participants also reflected on the fact that they could exercise compassion with others facing social exclusion in unique ways. Some of the facilitators and participants spoke about the clubs, communities, networks, and friendships they had developed because of their disability, and felt that they would not have established these unique relationships if they did not have a disability. Drawing on these examples, the children and youth explained that disability was not always something to think negatively about, and these instances reinforced how disability had also had a positive role in their lives. The following excerpts highlight some of the facilitator and participants' thoughts regarding the positivity surrounding disability, and how their disabilities enabled them in unique waysv:

"No matter the skills, I have a unique way to accomplish tasks - I constantly have to adapt to broken equipment."

"I want the movers to know that kids with disabilities can do stuff just as much or better than kids without." 
"I have a superpower ... I have ADHD. I am able to multitask in ways other people can't." "Sometimes it may take time for me to share my thoughts, but I still have them so give me time to think and share."

In reflecting on what the children and youth had to say and listening to their perspectives and lived experiences, I began to understand what it meant to be 'disabled,' and how disability works to conceptualize, re-conceptualize, establish, and also challenge normative ideas about children and childhood. These reflections prompted me to think critically as a coordinator, researcher, and university instructor about the key take-away messages these young people taught me, and how I felt transformed by working with them. I believe these messages are important to share with others who are thinking about organizing a workshop for children and youth with disabilities that aims to foster consultative, collaborative, and participatory practices.

\section{"Nothing About Us, Without Us"}

In 1993, the slogan "Nothing About Us, Without Us" was coined at an international disability rights conference in South Africa and caught the attention of Michael Masutha and William Rowland, two key figures of Disabled People South Africa, who further mobilized the slogan through their work on disability rights (Charlton, 1998). As the 21 st century has evolved, the slogan has been further embraced by grassroots disability activists. The slogan's meaning is based on the location and source of different types of oppression relating to disability, and the idea that decisions should not be made without consulting and including those most affected by their effects (Charlton, 1998). Given its objective to challenge power relations and amplify the voices of individuals facing different forms of oppression (Charlton, 1998), it is no surprise that this slogan became a central focus at the IECSS/STM workshop. "Nothing about us, without us" was the important key message that the children and youth told the Movers, including government officials, educators, doctors, lawyers, academics, policy makers, and professionals working with children and youth. They challenged the Movers to think about how their decisions affect children with disabilities and asked them why they were often silenced, ignored, and excluded from participating in decisions that affect their everyday lives. One of the youth facilitators explained: "Often we feel like asking for things is impolite, but the language of human rights reminds us that this is not too much to ask."

The IECSS/STM children and youth reminded me of the ways in which researchers and coordinators must listen to what children and youth have to say, what they prefer, their 
suggestions, and then be open to adapting, altering, and reworking research plans if what they hear from the youth doesn't adhere to project objectives or assumptions. For children with disabilities, this means critically reflecting on the ways surveillance and control are often exercised in order to "stay on schedule," without the recognition of how diverse bodies, languages, actions, and forms of expression all work to produce different messages for children. Scholars have pointed to the cultural politics of childhood that are often disguised or socialized within helping professions for young people (Stephens, 1995) and especially for individuals with disabilities (Edelman, 1974). While many helpers who work with children with disabilities may indeed assist young people or see themselves as helpers, oftentimes these attempts to help become instances of control and monitoring (Edelman, 1974). The workshop highlighted the importance of adults relinquishing control to create participatory environments that do not mistakenly or intentionally control or govern young people participating in the workshops.

The workshop also reiterated the importance of ongoing evaluations of programs, models, and workshop designs to ensure meaningful participation. Specifically, it would be beneficial for future research to focus on understanding the ways in which alternative care structures of the workshop can be improved. While brief feedback focusing on the workshop was collected from the facilitators after the event ended, further research could focus on conducting interviews with former participants and facilitators to ask them how these structures could be enhanced or what they would change. In line with such evaluation is also ensuring that team members, policies, and practices support and foster inclusion for all participants. Another essential component is the role of collaborative multidisciplinary teams in planning, implementing, and executing workshops to diversify and enrich programs and promote inclusivity. These components are vital to promoting active engagement that enables children and youth with disabilities to participate fully and meaningfully, if they so wish. In order for this to happen, it is imperative that workshops meet the needs of individual children and their families and can adapt and shift flexibly to accommodate differences. I believe it is critical for researchers and organizers to reflect on these components if they intend on creating collaborative and consultative environments for children with disabilities. If not, we may end up reinforcing and sustaining that same marginality that we initially intended to challenge and contest.

One of the most important reminders that young people revealed was the strength of the youth-led approach fostered by the STM model. As I observed what the facilitators proposed and 
what the participants contributed in the discussions, not only did I learn about the day-to-day realities of children and youth with disabilities and their proposed solutions and recommendations, I was also reminded of the importance of the simple act of listening. Sadly, as I listened, what I heard were many participants and facilitators explaining their struggle to access equitable services, especially those that foster collaborative, consultative, and participatory practices.

\section{Conclusion}

As the National STM Coordinator, I was reminded by children and youth with disabilities how marginality and relationality shape their everyday lives. These experiences ultimately shape the environments, interactions, and relationships for researchers and professionals working with young people. I was challenged to think critically about the concepts of marginality and relationality and how they work to disrupt adult-centric views about young people, disability, and participation. I share these reflections in an attempt to highlight the key truths that young people taught me about both the negative and positive realities of disability that worked to disrupt and challenge the concept of disability more broadly. In reflecting on the strengths of the STM model and the instances where adult-centric assumptions were challenged and modified, I hope that others will carry these important messages forward in their planning to create meaningful, consultative, and collaborative participatory spaces for children and youth with disabilities. As a STM participant reminds us: "It shouldn't be only the person with the disability to always adapt."

\section{Notes}

i For information on the Centre, view the website at www.carleton.ca/landonpearsoncentre ii For more information on the IECSS project, view the website at https://iecss.blog.ryerson.ca/ iii Quotes derived from STM Facilitators (aged 18-25) and Participants (aged 10-18), Oct 13-14, 2018 (see STM Report by Benincasa, St. Dennis, \& Caputo, 2018).

iv Quotes derived from STM Facilitators (aged 18-25) and Participants (aged 10-18), Oct 13-14, 2018 (see STM Report by Benincasa, St. Dennis, \& Caputo, 2018).

v Quotes derived from STM Facilitators (aged 18-25) and Participants (aged 10-18), Oct 13-14, 2018 (see STM Report by Benincasa, St. Dennis, \& Caputo, 2018). 


\section{References}

Benincasa, E., St. Dennis, A., \& Caputo, V. (2018). IECSS/Shaking the Movers Report 2018:

Can Disability Be Positive? Ottawa, ON: Retrieved from https://carleton.ca/landonpearsoncentre/shaking-the-movers/

Caputo, V. (2018). What Makes Shaking the Movers Unique? The Landon Pearson Centre for the Study of Childhood and Children's Rights. Carleton University: Ottawa, ON.

Charlton, J. (1998). Nothing About Us Without Us: Disability Oppression and Empowerment. University of California Press.

Clandinin, D. J., \& Connelly, F. M. (2000). Narrative inquiry: Experience and story in qualitative research. San Francisco, CA: Jossey-Bass.

Edelman, M. (1974). The Political Language of the Helping Professions. Politics \& Society, 4(3), 295-310.

Ellis, C. (2004). The ethnographic I: A methodological novel about autoethnography. Walnut Creek, CA: AltaMira Press.

Ellis, C., \& Bochner, A. P. (2000). Autoethnography, personal narrative, reflexivity: Researcher as subject. In N. K. Denzin \& Y. S. Lincoln (Eds.), Handbook of Qualitative Research (pp. 733-768). London: Sage.

Goodley, D. (2012). Dis/entangling critical disability studies. Disability \& Society, 28(5), 631644.

Linton, S. (1998). Claiming disability: Knowledge and identity. New York: New York University Press.

McGuire, A. (2016). War on Autism: On the Cultural Logic of Normative Violence. Ann Arbor: University of Michigan Press.

Mingus, M. (2011). Access Intimacy: The Missing Link. Leaving Evidence. Retrieved from https://leavingevidence.wordpress.com/2011/05/05/access-intimacy-the-missing-link/

Oliver, M. (1990). The Politics of Disablement: Critical Texts in Social Work and the Welfare State. London: Palgrave.

Pearson, L., \& Collins, T. (2011). Shaking the Movers: A Model for Collaborative Consultation with Children and Youth on Public Policy. Carleton University: Ottawa, ON.

Snyder, S., \& Mitchell, M. (2006). Cultural Locations of Disability. Chicago and London: University of Chicago Press.

Stephens, S. (1995). "Introduction: Children and the Politics of Culture in "Late Capitalism." In Children and the Politics of Childhood. Princeton, N.J: Princeton, University Press, pp. 35-41.

Sue, D. (2010). Microaggressions and Marginality. New Jersey: John Wiley \& Sons.

Wall, S. (2008). Easier said than done: Writing an autoethnography. International Journal of Qualitative Methods, 7, 38-53. 